\title{
Laparoscopic Surgeries in Urology: Initial Burgeoning Experience at National Transplant Centre, Nepal
}

Bijaya Mansingh Katwal ( $\nabla$ drbijaymansinghkatwal2020@gmail.com )

Shahid Dharma National Transplant Center https://orcid.org/0000-0002-2006-1420

Sharmila Koju

Shahid Dharma Bhakta National Transplant Center

Kiran Jang Kunwar

Shahid Dharma Bhakta National Transplant Centre

Pukar Chandra Shrestha

Shahid Dharma Bhakta National Transplant Centre

\section{Research article}

Keywords: First Donor Nephrectomy, Laparoscopic Surgery, Nephrectomy, Transplantation

Posted Date: May 1st, 2020

DOl: https://doi.org/10.21203/rs.3.rs-19960/v1

License: (c) (i) This work is licensed under a Creative Commons Attribution 4.0 International License. Read Full License 


\section{Abstract \\ Background}

This study focuses on laparoscopic surgery experiences at Shahid Dharma Bhakta National Transplant Centre (SDNTC) which could enable the patients to gain knowledge regarding its benefits than conventional way of surgery. The present study finds out the frequency of various forms of nephrectomy based on laparoscopic surgery. Moreover, this study accomplishes lap donor nephrectomy of kidney transplantation which is of its first kind in this part of country.

\section{Methods}

We retrospectively reviewed the in-patient medical records at SDNTC from November 2017 to January 2019. Laparoscopic surgery was performed in 50 patients. The demographic data, indication for surgery, duration and peri-operative outcomes were analyzed.

\section{Results}

Out of 50 cases, 34 (68\%) had undertaken lap simple nephrectomy, 6 (12\%) were lap pyeloplasty, 6 (12\%) nephro ureterectomy, $1(2 \%)$ radical nephrectomy, $1(2 \%)$ lap donor nephrectomy for kidney transplantation, $1(2 \%)$ heminephrectomy and 1 (2\%) nephrectomy of hydronephrotic non functioning left crossed ectopia. The lap donor nephrectomy of a case for kidney transplantation is the first laparoscopic donor nephrectomy of Nepal undertaken by Nepalese team at SDNTC. Amongst all nephrectomy, 27 (54\%) patients were operated on right side while 23 (46\%) patients on left side. The median age of the patients was 38.56 years comprising of $32(64 \%)$ male and $18(36 \%)$ female. Transperitoneal approach was used in all 50 (100\%) cases. The respective median operative time and hospital stay was 122.3 minutes and 5 days. The mean estimated blood loss was $74.1 \mathrm{cc}$ where two patients required blood transfusion intra-operatively. Post-operatively, 1 (2\%) patient had hematoma which was managed conservatively. Two cases (4\%) patients were converted to open surgery.

\section{Conclusions}

Laparoscopic surgery is feasible and safe procedure at our government setup hospital with least cumbersome procedure and minimum complication associated with it.

\section{Background}

In 1990, first lap nephrectomy was performed by Ralph Clayman. ${ }^{1}$ Laparoscopic surgery has significant advantages over conventional incisional surgery. Because of this, there has been increasing number of successful laparoscopic radical and simple nephrectomies, partial nephrectomy, laparoscopic donor nephrectomy in case of renal transplantation, excision of renal cyst, ureteral reimplantation, pyeloplasty, stone surgery, ureterolysis and bladder neck suspension ${ }^{2-4}$. Reports have proven efficacious with minimal morbidity, reduced post operative pain, reduced chest and wound complication; decreased length of hospital stay, rapid return to normal activities and improved cosmetics compared to open urologic surgery. ${ }^{2-4}$ In present study, an initial burgeoning experience of fifty cases undertaken lap surgery was shared indicating the first healthy donor nephrectomy for kidney transplantation in Nepal at our centre SDNTC.

\section{Methods}


Over a period of 14 months commencing from November 2017 to January 2019, fifty laparoscopic cases (32 male, 18 female age ranging from 10-60 years) were performed. We analyzed the demographic data, indications for surgery, route of approach and preoperative outcomes. The lap surgery was carried out in well set-up at SDNTC by using Ethicon Endo-surgery machine procured from Guaynabo, Puerto Rico 00969 USA.

\section{Patient's Preparation and Laparoscopic Surgery Procedure}

The patients were placed in a lateral (kidney) position. Pneumoperitoneum was created with visual trocar of $10 \mathrm{~mm}$ about 2.5 $\mathrm{cm}$ superolateral to umbilicus which was also a camera port. Laparoscopic nephrectomy was performed using 3 to 4 ports 10 $\mathrm{mm}$ camera port, other $10 \mathrm{~mm}$ and $5 \mathrm{~mm}$ working port in subcoastal region, or in hypogastric region (depending on left or right side getting operated) and other $10 \mathrm{~mm}$ port was placed as per requirement for bowel, kidney and liver retraction. The renal artery, vein and ureter were secured with hemolock clips (size $10 \mathrm{~mm}, 5 \mathrm{~mm}$ ) and divided with scissor. After finishing the procedure, the specimen was extracted through an extension of incision to $4-5 \mathrm{~cm}$ of $10 \mathrm{~mm}$ (lower or lateral) port.

\section{Results}

Patient characteristic features were presented in Table 1. There were 32 males and 18 females with a median age of 38.56 years (IQR: $10-60)$ in those cases $27(54 \%)$ right and 23 (46\%) left sided surgery were performed. Transperitoneal approach was performed in all $50(100 \%)$ cases. The surgery was performed for various disease conditions. The indications were non functioning kidney in 34 patients (68\%), Pelvi-Ureteric Junction (PUJ) obstruction in $6(12 \%)$, renal cell carcinoma in 1 (2\%), Vesico Ureteric Junction (VUJ) stricture with VUJ stone leading to non functioning kidney in 6 patients (12\%), non functioning crossed ectopia of left kidney in $1(2 \%)$, non functioning left horseshoe kidney in $1(2 \%)$ and $1(2 \%)$ is laparoscopic healthy donor for renal transplantation (Table no. 2).

Table 1: Patients' Characteristic Features and Access of Lap Surgery

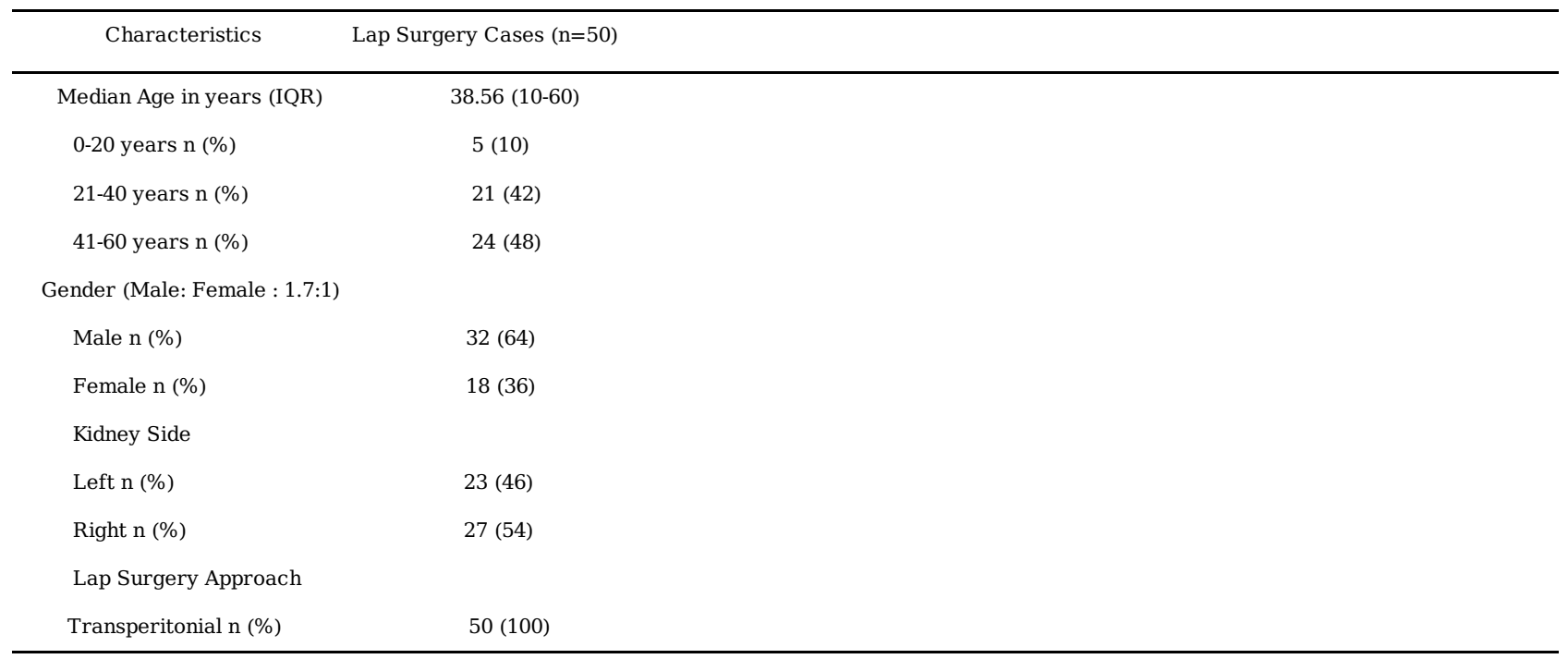

Table 2: Indications of Lap Surgery 


\begin{tabular}{lc}
\hline Renal Pathology & Number (\%) \\
\hline Non Functioning Kidney & $34(68)$ \\
PUJ Obstruction & $6(12)$ \\
Renal Cell Carcinoma & $1(2)$ \\
VUJ Stricture & $6(12)$ \\
Non Functioning Crossed Ectopia & $1(2)$ \\
Non Functioning Horseshoe Kidney & $1(2)$ \\
Healthy Donor For Kidney Transplantation & $1(2)$ \\
\hline
\end{tabular}

Surgical data are shown in Table 3; operating time, the rate of intraoperative complications and the rate of conversion to open surgery. The median operating time was 122.3 minutes (IQR: 45-255). Two (4\%) patients were converted to an open nephrectomy because of massive adhesion and bleeding but only 2 pint of blood was transfused in one patient. The median estimated blood loss was $74.1 \mathrm{cc}$ (IQR: 20-350) whereas median drain was projected to be $137.1 \mathrm{cc}$ (IQR: 0-340). All of 50 patients received adequate analgesic medication viz a viz paracetamol and tramadol. The median hospital stay was 4.64 days (IQR: 2-8).

Table 3: Lap Surgery Outcome of the Patients

\begin{tabular}{lc}
\hline Outcome & Lap Surgery Cases (n=50) \\
\hline Operating time (minutes), median (IQR) & $122.3(45-255)$ \\
Hospital stay (days), median (IQR) & $4.64(2-8)$ \\
Intraoperative complications, number (\%) & $2(4)$ \\
Conversion to open surgery, number (\%) & $2(4)$ \\
Blood loss (cc), median (IQR) & $74.1(20-350)$ \\
Drain (cc), median (IQR) & $137.1(0-340)$ \\
& \\
\hline
\end{tabular}

\section{Discussion}

Laparoscopic surgeries can be taken as a safe, attractive and viable alternative to conventional open surgery. In comparison to open surgery the advantage of a less invasive surgical approach to urological disease is based on improved cosmetic results, patient comfort and shorter convalescence. . $1,5,6,7,8^{-10}$

In the present study, the transperitoneal approach has been taken as we were more familiar with this approach; it represented the standard access during laparoscopic training. The significant difference was not detected while comparing the transperitoneal to retroperitoneal laparoscopic approach, which is similar to other comparative studies. ${ }^{9,10}$ The operating time depended mostly on the individual pathological condition like number of renal arteries, size of the kidney, perirenal adhesion, previous surgeries, BMI of the patient and experience of surgeon rather than the laparoscopic access technique used.

In adult patients, prospective $\mathrm{e}^{11,12}$ and retrosepective ${ }^{13,14}$ comparisons between open and laparoscopic nephrectomies have shown that chest complications, hospital stay, analgesic requirement, and time required to return to normal activities are reduced in laparoscopically treated patients. However, these reports have stated that laparoscopic procedure have significantly longer operative time (135-335 min). In our study, the median operative time was 122.3 minutes.

In 1992, Bolhme et al reported, 490 living donor nephrectomies series in which a major complication rate was $1.4 \%$ and a minor complication rate $13.6 \% .{ }^{12}$ In our study, we did not face any major complication but had $4 \%$ of minor complication 
which was managed conservatively. We have started laparoscopic donor nephrectomy for kidney transplant patient and this is the only centre doing laparoscopic donor nephrectomy in Nepal till date.

\section{Conclusions}

Laparoscopic surgery is safe and feasible procedure at our government setup and also challenging for urologists which requires surgical skills and laparoscopic expertise for consistently good outcomes. Regarding the inherent benefits for patients in terms of reduced pain level, faster recovery and improved cosmetic result, it has become the standard approach for urologic surgery at our institution.

\section{Abbreviations}

PUJ

Pelvi-Ureteric Junction; SDNTC:Shahid Dharma Bhakta National Transplant Centre;

VUJ

Vesico Ureteric Junction (VUJ)

\section{Declarations}

\section{Acknowledgement}

I would like to thank all patient participants who had undertaken lap surgery as their part of procedure for renal problems. I would like to thank Dr. Narayan Prasad Bhusal who has helped me during surgery. I would like to give an immense acknowledgement for the thorough revision of this article by Mr. Narayan Gautam, Department of Biochemistry, Universal College of Medical Sciences, Bhairahawa, Nepal.

\section{Authors' contributions}

BMK proposed the protocol and procedural functioning of the whole study. KJK and PCS supported in the procedural functioning of the study subjects. SK

contributed to statistical analysis and manuscript writing. All authors read and approved the

final manuscript.

\section{Funding}

No funding was obtained for this study

\section{Availability of data and materials}

The datasets used during the current study are available from the corresponding author on reasonable request.

\section{Ethics approval and consent to participate}

This retrospective study was conducted in the national transplant centre in a governmental setup under the auspices of the Director of SDNTC (Dr. Pukar Chandra Shrestha) who is the co-author of this manuscript as well. All patients were notify regarding the procedure they were going to intervene and their verbal as well as written consent were taken before nephrectomy.

\section{Consent for publication}

Not applicable.

\section{Competing interests}


The authors declare that they have no competing interests.

\section{Author details}

${ }^{1}$ Department of Urology \& Kidney Transplantation, Shahid Dharma Bhakta National Transplant Centre (SDNTC), Bhaktapur, Nepal

\section{References}

1. Clayman RV, Kavoussi LR, Soper NJ, et al. Laparoscopic nephrectomy (letter). N Engl JMed. 1991;324:1370-1.

2. Kerbl K. Clayman Rv: Advances in laparoscopic renal and ureteral surgery. Eur Urol. 1994;25:1-6.

3. Janetschek G. Laparoscopic interventions in urology. Wien Klin Wochenschr. 1995;107:70-6.

4. Barrett PH, Fentie DD, Taranger L. Laparoscopic radical nephrectomy with morcellation (poster P6-19), Presented at 15th World Congress on Endourology. Edinburfh UK, August 31-Spetember 3, 1997.

5. Coptcoat MJ, Wickman JEA. Laparoscopy in urology. Min Inv Ther. 1992;1:337.

6. Rassweiler JJ, Henkel TO, Potempa DM, Coptcoat M, Alken P. The technique of transperitoneal laparoscopic nephrectomy, adrenalectomy, and nephroureterctomy. Eur Urol. 1993;23:425.

7. Gill IS, Kavoussi LR, Clayman RV, Ehrlich R, Evans R, Fuchs G, Gersham A, Hulbert JC, McDougall EM, Rosenthal T, Schuessler WW, Shepard T. Complications of laparoscopic nephrectomy in 185 patients: a multi-institutional review. J Urol. 1995;154:479.

8. Janetschek G, Rassweiler J, Griffith D. Laparoscopic Surgery in Urology. New York: Thieme; 1996.

9. Rassweiler JJ, Stock C, Frede T, Seemann O, Henkel T, Alken P. Transperitoneale und retroperitoneale laparoskopische Nephrektomie im Vergleich zur konventionellen Nephrektomie. Urologe A. 1996;35:215.

10. McDougall EM, Clayman RV. Laparoscopic nephrectomy for benign disease: comparison of the transperitoneal and retroperitoneal approaches. J Endourol. 1996;10:45.

11. Eden CG, Haigh AC, Carter PG. Laparoscopic nephrectomy results in better post operative pulmonary function. J Endourol. 1994;8:419-23.

12. Wilson BG, Deans GT, Kelly J, et al. Laparoscopic nephrectomy; initial experience and cost implications. Br J Urol. 1995;75:276-80.

13. Kerbel k, Clayman RV. Advances in laparoscopic renal and ureteral surgery. Eur Urol. 1994;25:1-6.

14. Doublet JD, Barreto HS, Degremont AC, et al. Retroperitoneal nephrectomy: comparison of laparoscopic with open surgery. world J Surg. 1996;20:713-6. 